\title{
On-Line Electrical Impedance Measurement for Monitoring Blood Viscosity during On-Pump Heart Surgery
}

\author{
G.A.M. Pop ${ }^{a}$ T.L.M. de Backer ${ }^{b}$ M. de Jong ${ }^{b}$ P.C. Struijk ${ }^{c}$ L. Moraru ${ }^{a}$ \\ Z. Chang ${ }^{d}$ H.G. Goovaerts ${ }^{e}$ C.J. Slagera A.J.J.C. Bogers ${ }^{b}$
}

aDepartment of Cardiology, Hemodynamics Laboratory, b Department of Cardiothoracic Surgery, Thoraxcenter, and 'Department of Gynaecology, Erasmus Medical Center, Rotterdam; dDepartment of Microelectronics, Delft University of Technology, Delft, and e Department of Clinical Physics and Informatics, Vrije University, Amsterdam, The Netherlands

\section{Key Words}

Blood viscosity · Electrical impedance $\cdot$ On-pump heart surgery

\begin{abstract}
Background: The viscosity of blood $(\eta)$ as well as its electrical impedance at $20 \mathrm{kHz}$ at high shear rate depends on hematocrit, temperature, concentration of macromolecules and red cell deformability. The aim of our study was to investigate the relation between viscosity and electrical impedance in a heart-lung machine-like set-up, because during on-pump heart surgery considerable viscosity changes occur. Methods: Blood of 10 healthy volunteers was examined under temperature variation between 18.5 and $37^{\circ} \mathrm{C}$ at four different levels of hemodilution. Blood viscosity was examined with a golden-standard technique, i.e. a Contraves LS 30 Couette viscometer, and the results were compared with measurements of the electrical resistivity $(R)$ at $20 \mathrm{kHz}$ by a specially designed device in series with the tubing system of a heart-lung machine. All measurements were performed at a shear rate of $87 \mathrm{~s}^{-1}$. Results: Using stepwise multipa-
\end{abstract}

\section{KARGER}

Fax +41613061234

E-Mail karger@karger.ch

www. karger.com
(C) 2004 S. Karger AG, Basel

0014-312X/04/0365-0259\$21.00/0

Accessible online at: www. karger.com/esr rameter regression analysis (SPSS) a highly significant correlation was found $\left(r^{2}=0.882\right)$ between viscosity $(\eta)$ and resistivity (R). Adding the variables sodium ([Na+]) and fibrinogen ([Fibr]) concentration the coefficient of correlation further improved to $r^{2}=0.928$ and the relation became: $\eta=-0.6844+0.038 \mathrm{R}+0.038\left[\mathrm{Na}^{+}\right]+0.514$ [Fibr] . All coefficients showed a statistical significance of $p<0$. 001. Conclusions: Electrical impedance measurement is feasible in a heart-lung machine-like set-up and allows accurate continuous on-line estimation of blood viscosity; it may offer an adequate way to record and control viscosity changes during on-pump heart surgery.

Copyright @ $\odot 2004$ S. Karger AG, Basel

\section{Introduction}

Blood has non-Newtonian fluid dynamics characteristics, the most important of which is that its viscosity depends on shear rate $[1,2]$. At intermediate $\left(<50 \mathrm{~s}^{-1}\right)$ and especially at low $\left(<1 \mathrm{~s}^{-1}\right)$ shear rate the viscosity significantly increases, whereas at high shear rate $\left(>100 \mathrm{~s}^{-1}\right)$ blood behaves almost Newtonian and the viscosity only 
slightly drops with increasing shear rate [2]. The predominant cause of increasing viscosity when lowering shear rate is the occurrence of red blood cell (RBC) aggregation ('rouleaux formation') [3]. Normally in healthy persons, when the rising shear rate is $>100 \mathrm{~s}^{-1}$, all $\mathrm{RBC}$ aggregates are dispersed [1] and RBC deformability becomes an important factor determining blood viscosity [3]. Other important determinants of blood viscosity are the hematocrit (number of cell-cell interactions), the temperature and the concentration of macromolecules (cell-protein interactions) in the suspending medium, influencing the intensity of red cell-cell interactions [1-4].

Interestingly, the electrical impedance of blood shows a similar dependency of the most important viscosity determining parameters [5,6]. The electrical resistivity of whole blood, measured at low frequency $(20 \mathrm{kHz})$, is highly dependent on hematocrit, because the isolating membranes of the RBCs are not conducting below $100 \mathrm{kHz}$ [7, 8]. Similar to blood viscosity, the electrical impedance of blood will increase at low shear rate because of RBC aggregation (rouleaux formation) [5], which diminishes the accessible conducting plasma volume. At higher shear rates the electrical impedance, measured in parallel with the flow streamlines, is dependent on the deformability of the RBC [9]. Similar to viscosity, the electrical resistivity (at $20 \mathrm{kHz}$ ) of blood will reach an almost constant plateau for shear rates $>100 \mathrm{~s}^{-1}$ and the level of the plateau is dependent of the red cell deformability [9]. Also similar to viscosity is that both a decrease of temperature as well as an increase of macromolecules (especially fibrinogen) in the medium will increase the electrical impedance of blood [5, 10]. Electrical impedance measurement has been used for determining hematocrit on-line [11] but variation in temperature and concentration of macromolecules (like fibrinogen) make blood resistivity more correlated with whole blood viscosity than with hematocrit. For all these reasons, measuring blood resistivity might provide, under certain circumstances, an easier alternative for the estimation of blood viscosity.

The aim of our study was to compare in a direct way blood viscosity determined by a Couette viscometer with electrical resistivity of blood determined by the four electrodes measuring technique at low frequency $(20 \mathrm{kHz})$. Measuring conditions were adapted to the situation of onpump open-chest heart surgery as in this condition considerable viscosity changes occur $[12,13]$; monitoring these viscosity changes by an on-line electrical resistivity measurement device might be of clinical benefit.

\section{Material and Methods}

\section{Population and Experimental Set-Up}

After informed consent had been obtained from 10 healthy male volunteers with a mean age of 33 (range 25-50) years, $300 \mathrm{ml}$ blood was taken from the antecubital vein. Two volunteers were smokers. No history of infection was present in the weeks before blood donation. Blood was heparinized $(40 \mathrm{U} / \mathrm{ml})$ and placed in a heart-lung machine-like set-up (fig. 1). This set-up consisted of a centrifugal pump, a reservoir for pediatric use and a Tygon ${ }^{\circledR}$ tubing system with restricted length. The temperature was controlled by a Heater$\operatorname{Cooler}^{\circledR}$ (Stöckert, Munich, Germany) and flow was measured instantaneously by an electromagnetic flow probe $\left(\mathrm{H} 6 \mathrm{xl}^{\circledR}\right.$, Transonic Systems Inc., Ithaca, N.Y., USA).

\section{Viscosity Measurement}

Blood viscosity was determined with the Contraves LS 30 Couette viscometer (Zürich, Switzerland), allowing measurements at different temperatures. Blood viscosity was determined at the highest shear rate $\left(87 \mathrm{~s}^{-1}\right)$ that could be reliably applied. A corresponding shear rate at the location of the electrical resistivity measurement within the heart-lung machine was obtained by selecting a mean flow of $442 \mathrm{~cm}^{3} / \mathrm{min}$ calculated according to the formula: shear rate $=4 \times$ mean velocity/radius [2].

\section{Impedance Measurement}

The impedance measurement system consisted of four stainless steel electrode rings mounted in-line with the wall (fig. 2); the two outer current delivery electrodes were positioned at equal distances from the two inner measurement electrodes. The electrodes were connected with an impedance-measuring instrument (Goovaerts Instruments, Kortenhoef, The Netherlands) [14]. Between the current electrodes, an alternating $(20-\mathrm{kHz})$ current of $<100 \mu \mathrm{A}_{\mathrm{rms}}$ was applied and between the measurement electrodes the voltage was recorded. Blood cells are not altered at these low currents [15]. Calibration of the device was performed with physiologic $0.9 \% \mathrm{NaCl}$ solution in a special impedance-measuring instrument (CD Leycom, Zoetermeer, The Netherlands). Using the obtained calibration constant, the specific resistivity of blood in the device was calculated.

\section{Physiological Variables}

The condition of on-pump heart surgery was simulated by inducing hypothermia until $18.5^{\circ} \mathrm{C}$ and increasing the temperature subsequently to 25,32 and $37^{\circ} \mathrm{C}$. Temperature stability could be maintained within a reading of $0.1^{\circ} \mathrm{C}$. The other important parameter of hemodilution was varied by adding a plasma expander (Gelofusine ${ }^{\circledR}$, B. Braun, Melsungen, Germany). Therefore, baseline hematocrit and three lower hematocrits (until 22\%) were obtained. For each hematocrit value, measurements were performed at four different temperatures.

For each hematocrit sample, sodium $\left(\mathrm{Na}^{+}\right)$, hematocrit $(\mathrm{Hct})$ and $\mathrm{pH}$ were measured in a GEM Premier 3000 (Instrumentation Laboratory, Lexington, Mass., USA) at the beginning $\left(18.5^{\circ} \mathrm{C}\right)$ and at the end $\left(37^{\circ} \mathrm{C}\right)$ of the viscosity measurements. The interval between measurements at each dilution and at the four different temperatures (T) was $<20 \mathrm{~min}$.

\section{Statistics}

Unless otherwise stated, all results are expressed as mean $\pm \mathrm{SD}$. The paired Student's t test was used to compare differences between 


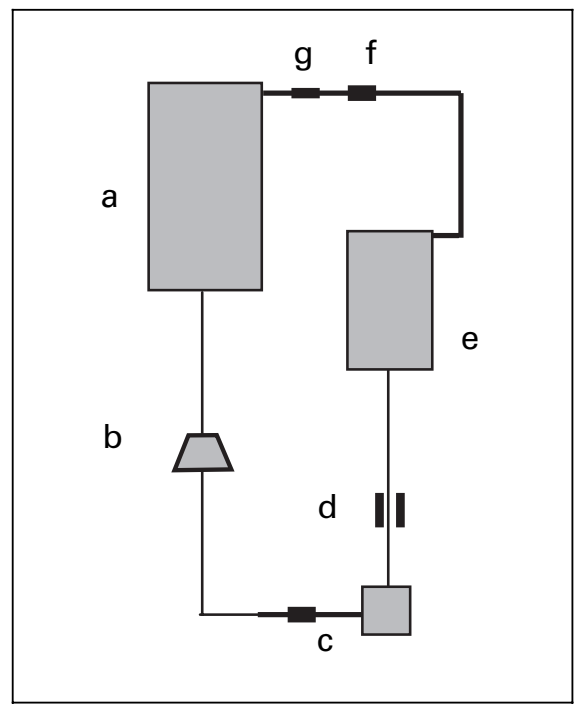

Fig. 1. Schematic diagram of the 'heart-lung machine'-like set-up. a Venous reservoir, Polystan Safe Micro, Copenhagen, Denmark. b Centrifugal pump, Biomedicus BP-50 Medtronic, Eden-Prairie, Minn., USA. c Heater-Cooler, Stöckert, Munich, Germany. d Flow probe H6xl, Transonic Systems, Inc., Ithaca, N.Y., USA. e Heatexchanger, Polystan Safe Micro, Copenhagen, Denmark. f Impedance device (see fig. 2) g Temperature probe, Mallinckrodt Medical, St. Louis, Mo., USA.

$\mathrm{pH}, \mathrm{Na}^{+}$and $\mathrm{Hct}$ at 18.5 and $37^{\circ} \mathrm{C}$. Multiple stepwise regression was applied to relate viscosity and resistivity to $\mathrm{Hct}, \mathrm{T}, \mathrm{Na}^{+}, \mathrm{Fibr}$ and $\mathrm{pH}$. Similarly, a regression model was developed to predict viscosity from resistivity. All statistics were calculated using the software package SPSS (version 9.0 for Windows, Microsoft). A p value of $<0.05$ was considered to be statistically significant.

\section{Results}

The intake Hct varied from 37 to $51 \%$ (44.7 (SD 4.1)). All individuals had normal levels of fibrinogen, varying from 1.98 to $2.85 \mathrm{~g} / 1$ with a mean of 2.33 (SD 0.27).

Relating blood viscosity $(\eta)$ in a multiparameter model with stepwise regression analysis to the variables Hct and $\mathrm{T}$ yielded a correlation coefficient $\left(\mathrm{r}^{2}\right)$ of 0.888 for a logarithmic relation. Adding $\mathrm{pH}, \mathrm{r}^{2}$ increased to 0.903 and after adding $\mathrm{Na}^{+} \mathrm{r}^{2}$ increased to 0.908 . Finally, adding fibrinogen raised $r^{2}$ minimally to 0.911 . Considering a rise in $r^{2}<0.005$ as clinically insignificant, the subsequent formula was obtained:

$\ln (\eta)=-5.129+0.0276 \mathrm{Hct}-0.0223 \mathrm{~T}+0.0026\left[\mathrm{Na}^{+}\right]$

$+0.801 \mathrm{pH}$

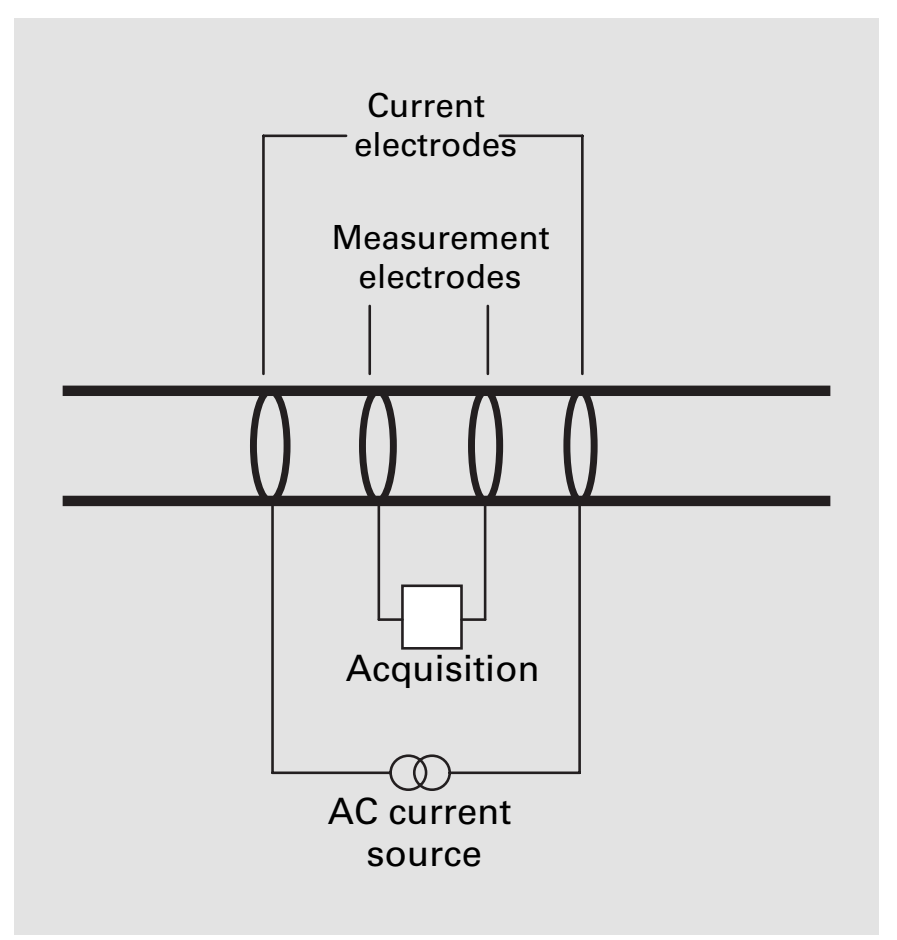

Fig. 2. Blood impedance-measuring device for heart-lung machine.

where $\eta=$ blood viscosity $(\mathrm{mPa} \cdot \mathrm{s})$, Hct $=$ hematocrit $(\%)$, $\mathrm{T}=$ temperature $\left({ }^{\circ} \mathrm{C}\right),\left[\mathrm{Na}^{+}\right]=\mathrm{Na}^{+}$concentration $(\mathrm{mmol} / \mathrm{l})$, and $\mathrm{pH}=$ logarithmic acid-base balance. All coefficients were highly significant $(\mathrm{p}<0.001)$.

Relating the specific electrical resistivity $\mathrm{R}$ to the variables Hct and $\mathrm{T}$ yielded for a logarithmic relation an $\mathrm{r}^{2}=$ 0.957. Adding $\mathrm{Na}^{+}$raised $\mathrm{r}^{2}$ to 0.974 . Adding $\mathrm{pH}$ and fibrinogen raised $\mathrm{r}^{2}$ minimally to respectively 0.976 and 0.977 ( $<0.001$ for all coefficients). Considering again a rise of $r^{2}<0.005$ as clinically insignificant, the subsequent formula was obtained:

$$
\ln (\mathrm{R})=5.157+0.0252 \mathrm{Hct}-0.0207 \mathrm{~T}-0.0039\left[\mathrm{Na}^{+}\right]
$$

where $\mathrm{R}=$ specific resistivity $(\mathrm{ohm} \cdot \mathrm{cm}), \mathrm{Hct}=$ hematocrit $(\%), \mathrm{T}=$ temperature $\left({ }^{\circ} \mathrm{C}\right)$, and $\left[\mathrm{Na}^{+}\right]=\mathrm{Na}^{+}$concentration $(\mathrm{mmol} / \mathrm{l})$.

Relating blood viscosity to the specific electrical resistivity showed $r^{2}=0.882$. An overview of the data is depicted in figure 3. Adding $\left[\mathrm{Na}^{+}\right]$raised $\mathrm{r}^{2}$ to 0.921 and adding fibrinogen concentration raised $\mathrm{r}^{2}$ to 0.928 . There was a clinically non-significant further increase to $r^{2}=$ 0.930 , when the initial $\mathrm{pH}$ was entered $(\mathrm{p}<0.0001$ for all coefficients). Therefore, the relation between viscosity 
Fig. 3. Relation between measured viscosity and measured resistivity of blood at $20 \mathrm{kHz}$.
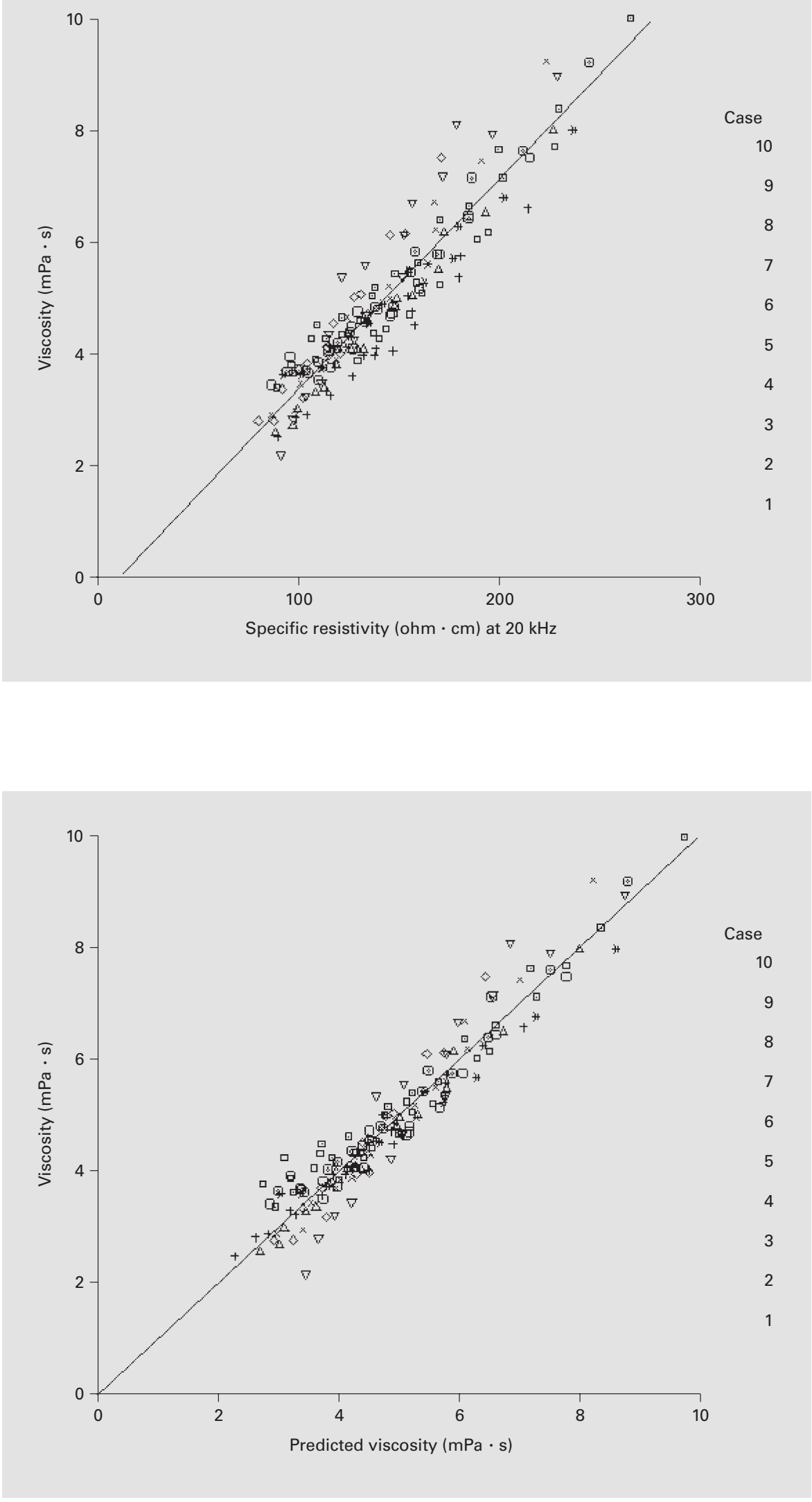

Fig. 4. Measured viscosity plotted against viscosity as predicted by equation 3 . 
and the specific electrical resistivity adding the variables $\left[\mathrm{Na}^{+}\right]$and $[\mathrm{Fibr}]$ for all Hcts and temperatures became:

$$
\eta=-0.6844+0.038 \mathrm{R}+0.038\left[\mathrm{Na}^{+}\right]+0.514[\text { Fibr }]
$$

where $\eta=$ blood viscosity $(\mathrm{mPa} \cdot \mathrm{s}), \mathrm{R}=$ specific resistivity measured at $20 \mathrm{kHz}$ in $(\mathrm{ohm} \cdot \mathrm{cm}),\left[\mathrm{Na}^{+}\right]=\mathrm{Na}^{+}$concentration $(\mathrm{mmol} / \mathrm{l})$, and $[\mathrm{Fibr}]=$ fibrinogen concentration $(\mathrm{g} / \mathrm{l})$.

The measured viscosity is plotted against the predicted value of blood viscosity in figure 4 .

\section{Comment}

In this experimental study we examined a wide range of changes of human blood viscosity as a function of hematocrit and temperature in a set-up which closely resembles the situation of on-pump open-chest heart surgery and compared these with variations in blood resistivity. All measurements were done at a comparable high shear rate of $87 \mathrm{~s}^{-1}$ under which blood of healthy persons reaches Newtonian $[1,2]$ behavior and both viscosity and electrical resistivity asymptotically reach a plateau [6,9]. A remarkably high correlation between viscosity and electrical resistivity was found.

Parameters determining resistivity as well as viscosity of blood showed to have almost the same effect except for sodium. The physiologic variation of sodium in whole blood ranges from 135 to $145 \mathrm{mmol} / \mathrm{l}$, which perfectly fits with our measurement results $(138 \pm 7.4 \mathrm{mmol} / \mathrm{l})$. From the regression analysis it appears that an increase of $10 \mathrm{mmol} / 1 \mathrm{Na}^{+}$results in a $3.9 \%$ decrease of electrical resistivity and a $3.1 \%$ increase of blood viscosity. The influence of the sodium level on blood resistivity is almost conform to the data predicted by Fuller [8] based on his plasma simulation model. A reduced deformability [16] and a reduced surface charge of the RBCs [17] may explain the influence of $\mathrm{Na}^{+}$on viscosity. Consequently, when the electrical resistivity is used as a parameter for blood viscosity at high shear, accuracy is improved by correcting for sodium level. However, normally $\mathrm{Na}^{+}$levels will change with $<10 \mathrm{mmol} / 1$ during heart surgery, because isotonic plasma expanders are used for hemodilution.

The influence of fibrinogen on blood viscosity and resistivity has been reported before [10, 18]. The influence of fibrinogen is particularly predominant at low shear rate. However, because the levels of fibrinogen in the healthy volunteers were low and similar, only a modest effect of fibrinogen was observed in this study. Nevertheless, the effect of fibrinogen on resistivity was statis- tically significant, illustrating the sensitivity of our measurements.

Considering the results obtained in this study, on-line determination of electrical resistivity of blood may be a valuable measurement method during on-pump heart surgery as a substitute of the more cumbersome repeated blood viscosity determination. Blood viscosity may be an important parameter to be evaluated $[12,13,19,20]$; measuring resistivity may be helpful to select optimal hemodilution [21] in order to counteract the negative effects of hyperviscosity. Several studies have demonstrated the presence of reduced $\mathrm{RBC}$ deformability after on-pump heart surgery and hypothermia has been shown as one of the causes [12]. Previous impedance studies have shown that reducing RBC deformability by hardening are reflected in increased electrical resistivity at $20 \mathrm{kHz}[9,22]$. The reduced RBC deformability may adversely affect capillary recruitment preventing adequate delivery of oxygen to tissue [23, 24]. Viscosity [2] as well as electrical impedance of blood [9] at high shear rate, as present in the tubes of the heart-lung machine, are dependent of RBC deformability. Clinical studies during on-pump heart surgery with use of our electrical impedance technique are warranted to investigate whether it reflects adequately blood viscosity level on-line and whether post-operative cerebral and renal dysfunction [25-27] might be partially due to hyperviscosity.

\section{Limitations of the Study}

The excellent squared correlation of electrical resistivity with hematocrit, temperature and $\mathrm{Na}^{+}$concentration (equation 2) indicates that the electrical resistivity of blood at a certain shear rate can be predicted accurately from these variables. In other words, the resistivity measurement shows a low signal-to-noise ratio, as the unexplained $\left(1-r^{2}\right) \cdot 100 \%$ fraction of the relation, i.e. $2.6 \%$, is very low [28]. In contrast, the correlation between blood viscosity and these three variables (equation 1) shows a somewhat smaller correlation, and the unexplained relative fraction is $9.2 \%$. It is possible that we missed a yet unknown variable, which might influence viscosity and not the electrical resistance. However, another more likely explanation might be that the viscosity measurements at lower levels show more noise. For rotational viscometers in general, the accuracy of measurements decreases for less viscous liquids and at highest shear rates [29]. Indeed, our data also show a decreasing correlation between viscosity and resistivity at the lower viscosity levels.

We measured blood viscosity at shear rate $87 \mathrm{~s}^{-1}$, because this was the maximal shear in the Contraves LS 
30. Using blood from healthy volunteers, we could expect that all RBC aggregates are dispersed at this shear rate [1, 2]. During a real coronary bypass surgery with a mean perfusion flow of $51 / \mathrm{min}$, shear rates are $>400 \mathrm{~s}^{-1}$. Then, also blood cells from patients will be fully dispersed, especially as hematocrit is normally lowered by hemodilution before connecting the heart-lung pump; a lower hematocrit [2]. Nevertheless, future investigations have to elucidate the influence of a raised fibrinogen concentration or other proteins on the correlation between viscosity and electrical resistance at high shear rate in a patient population.

A blood oxygenator was not added in our experimental set-up because this would require too much donation of blood. However, in almost all blood samples measured with the GEM Premier 3000 (Instrumentation Laboratory) the oxygen saturation remained between 95 and 100\% during the entire experiment. Furthermore, Kameneva et al. [12] did not consider the oxygenator as a specific factor of mechanical stress in their study of decreased RBC deformability due to cardiopulmonary bypass. In our experimental set-up we focused on the major influence of hypothermia and hemodilution on blood viscosity and resistivity.

In our study the relation between electrical resistivity and blood viscosity is measured at high shear rate only. As blood has non-Newtonian characteristics, the viscosity will rise steeply at low shear rate, especially because of aggregation [1, 2]. Studies of electrical impedance, at frequencies in the range from 20 to $1,200 \mathrm{kHz}$ in blood and at low shear rate, suggest that a relation exists between blood capacitance and the aggregation tendency between RBCs [5]. This correlation between electrical impedance and viscosity at low shear rate has to be further defined.

Finally, in our study the described method to determine blood viscosity can be used only during the onpump time; however, during this time greatest viscosity changes are present, especially if more hypothermia is being applied.

\section{Conclusion}

Electrical resistivity measured on-line at relatively low frequency $(20 \mathrm{kHz})$ in a heart-lung machine-like set-up has a good correlation with blood viscosity at high shear rate. This shows that estimation of blood viscosity by a well-defined impedance measurement is feasible.

\section{Acknowledgments}

We thank Ron van Domburg, biostatistician, of the Department of Clinical Epidemiology of the Thoraxcenter Rotterdam for his critical review of the statistical analysis and interpretation of the data used in this paper.

\section{References}

1 Chien S: Shear dependence of effective cell volume as a determinant of blood viscosity. Science 1970;168:977-978.

2 Wells RE, Merrill EW: Influence of flow properties of blood upon viscosity-hematocrit relationships. J Clin Invest 1962;41:1591-1598.

3 Baskurt OK, Meiselman HJ: Cellular determinants of low-shear blood viscosity. Biorheology 1997;34:235-247.

4 Rand PW, Lacombe E, Hunt HE: Viscosity of blood under normothermic and hypothermic conditions. J Appl Physiol 1964;19:117-122.

5 Zhao T, Jacobson B, Ribbe T: Triple-frequency method for measuring blood impedance. Physiol Meas 1993; 14:145-156.

6 Visser KR: Electric properties of flowing blood and impedance cardiography. Ann Biom Eng 1989;17:463-473.

7 Hill DW, Thompson FD: The effect of haematocrit on the resistivity of human blood at $37^{\circ} \mathrm{C}$ and $100 \mathrm{kHz}$. Med Biol Eng 1975;182185 .
8 Fuller HD: The electrical impedance of plasma: A laboratory simulation of the effect of changes in chemistry. Ann Biom Eng 1991;19: 123-129.

9 Ninomiya M, Fujii M, Niwa M, Sakamoto K, Kanai $\mathrm{H}$ : Physical properties of flowing blood. Biorheology 1988;25:319-328.

10 Zhao TX, Jacobson B: Quantitative correlations among fibrinogen concentration, sedimentation rate and electrical impedance of blood. Med Biol Eng Comput 1997;35:181185.

11 Jaffrin MY, Fournier C: Comparison of optical, electrical, and centrifugation techniques for haematocrit monitoring of dialysed patients. Med Biol Eng Comput 1999;37:433439.

12 Kameneva MV, Undar A, Antaki JF, Watach MJ, Calhoon JH, Borovetz HS: Decrease in red blood cell deformability caused by hypothermia, hemodilution, and mechanical stress: Factors related to cardiopulmonary bypass. ASAIO J 1999;45:307-310.
13 Eiseman B, Spencer FC: Effect of hypothermia on the flow characteristics of blood. Surgery 1962;52:532-544.

14 Goovaerts HG, Faes TJ, Raaijmakers E, Heethaar RM: A wideband high-CMRR input amplifier and PLL-demodulator for multifrequency impedance measurement. Med Biol Eng Comput 1998:36:761-767.

15 Geddes LA, Baker LE: Principles of Applied Biomedical Instrumentation, ed 3. New York, Wiley, 1989, chapt 11, p 539.

16 Bronkhorst P. Red cell deformability; thesis, Utrecht 1996.

17 Jan KM, Chien S: Influence of the ionic composition of fluid medium on red cell aggregation. J Gen Physiol 1973;61:655-668.

18 Weaver JPA, Evans A, Walder DN: The effect of increased fibrinogen content on the viscosity of blood. Clin Sci 1969:36:1-10.

19 Grotta J, Ackerman R, Correja J, Fallick G, Chang J: Whole blood viscosity parameters and cerebral blood flow. Stroke 1982;13:296-302.

Pop/de Backer/de Jong/Struijk/Moraru/ Chang/Goovaerts/Slager/Bogers 
20 Kee DB, Wood JH: Rheology of the cerebral circulation. Neurosurgery 1984;15:125-131.

21 Treib J, Haass A, Pindur G, Grauer MT, Wenzel E, Schimrigk K: All medium starches are not the same: Influence of the degree of hydroxyethyl substitution of hydroxyethyl starch on plasma volume, hemorrheologic conditions, and coagulation. Transfusion 1996;36:450 455.

22 Fujii M, Nakajima K, Sakamoto K, Kanai H: Orientation and deformation of erythrocytes in flowing blood. Ann NY Acad Sci 1999;20:245261.

23 Chien S, Usami S, Dellenback RJ, Gregersen MI: Shear-dependent deformation of erythrocytes in rheology of human blood. Am J Physiol 1970;219:136-142.
24 Simchon S, Jan K, Chien S: Influence of reduced red cell deformability on regional blood flow. Am J Physiol 1987;253:H898-H903.

25 Newman MF, Kirchner JL, Philips-Bute B, Gaver V, Grocott H, Jones RH: Longitudinal assessment of neurocognitive function after coronary artery bypass surgery. $\mathrm{N}$ Engl $\mathrm{J}$ Med 2001;344:395-402.

26 Broman M, Kallskog O: The effects of hypothermia on renal function and haemodynamics in the rat. Acta Physiol Scand 1995;153:179184.
27 Mangano CM, Diamondstone LS, Ramsay JG, Aggarwal A, Herskowitz A, Mangano DT: Renal dysfunction after myocardial revascularization: Risk factors, adverse outcomes, and hospital resource utilization. Ann Intern Med 1998;128:194-203.

28 Altman DG: Practical Statistics for Medical Research. New York, Chapman \& Hall/CRC, 1999, pp 297-305.

29 Chien S: Rotational viscometers; in Chien S, Dormandy J, Ernst E, Matrai A (eds): Clinical Hemorheology. Applications in Cardiovascular and Haematological Disease, Diabetes, Surgery and Gynecology. Dordrecht, Nijhoff, 1987, pp 31-37. 